\title{
Erratum
}

\section{Hexachlorobenzene Residues and Effects on Esterase Activities in Pre-Weanling Rats after a Reciprocal Transfer between HCB-Treated and Control Dams}

C. E. Mendoza*, B. Collins, J. B. Shields, and G. W. Laver

Chemical Safety Bureau, Food Directorate, Health Protection Branch, National Health and Welfare,

Ottawa, Ontario K1A OL2, Canada

Arch. Toxicol. 38, 191-199 (1977)

Delete from the footnote on Table 2 the statement "Lines are drawn only when the difference between averages is." Lines not marked by asterisks indicate that the difference between means is not significant. 